\title{
A RELAÇÃo ESTABELECIDA ENTRE A FORMAÇÃO PROFISSIONAL E O ENSINO REGULAR: FALAM OS JOVENS APRENDIZES ${ }^{12}$
}

\author{
Angelita de Oliveira Almeida ${ }^{3}$ \\ Inara Barbosa Leão 4
}

\begin{abstract}
Resumo
Este artigo tem por objetivo demonstrar como as atividades do Programa do Jovem Aprendiz tiveram influências na escola regular. Uma das condições para que o aprendiz participe do Programa, é estar matriculado no ensino fundamental, médio ou técnico, o que implica em uma tripla jornada diária. Neste estudo optamos pelo referencial teórico metodológico do materialismo histórico dialético, por oferecer subsídios para pensar a sociedade e os meios de produção em sua totalidade, pelas suas contradições e historicidade. Procuramos abarcar os mecanismos que fizeram e fazem com que esta formação se mostre como difusora da ideologia que garante a reprodução de uma classe social subordinada ao capital.
\end{abstract}

Palavras-chave: Educação Profissional; Estado; Capital.

\section{Resumen}

Este artículo tiene por objetivo demostrar cómo las actividades del Programa del Joven Aprendiz tuvieron influencias en la escuela regular. Una de las condiciones para que el aprendiz participe del Programa, es estar matriculado en la enseñanza fundamental, media o técnica, lo que implica una triple jornada diaria. En este estudio optamos por el referencial teórico metodológico del materialismo histórico dialéctico, por ofrecer subsidios para pensar la sociedad y los medios de producción en su totalidad, por sus contradicciones e historicidad. Buscamos abarcar los mecanismos que hicieron y hacen que esta formación se muestre como difusora de la ideología que garantiza la reproducción de una clase social subordinada al capital.

Palabras clave: Educación Profesional; Estado; Capital.

\footnotetext{
${ }^{1}$ DOI: https://doi.org/10.22409/tn.16i30.p10094

${ }^{2}$ Este artigo é parte da pesquisa obtida para obtenção do título de mestre, no Programa de PósGraduação em Educação, na Universidade Federal de Mato Grosso do Sul, no ano de 2011.

${ }^{3}$ Professora Adjunta I da Universidade Federal do Tocantins. Graduada em Administração pela UFV. Mestre em Educação pela UFMS. Doutoranda em Educação pela UFU. Pesquisadora na área sobre Trabalho, Sociedade e Educação. E-mail: angelita.almeida@uft.edu.br

${ }^{4}$ Professora titular da Universidade Federal de Mato Grosso do Sul. Graduada em Psicologia pela Faculdade Dom Aquino de Filosofia de Ciências e Letras. Mestre em Educação pela UFMS. Doutora em Psicologia Social pela PUC/SP. Pesquisadora na área sobre Aspectos psicossociais da educação e do trabalho. E-mail: inarableao@hotmail.com
} 


\section{Introdução}

Tratamos durante este estudo o fato de presenciarmos desde o final do século $X X$ e início deste século $X X I$, um aumento de programas/projetos de formação e/ou qualificação profissional direcionados aos jovens brasileiros, filhos (as) da classe trabalhadora. Isto por causa do processo de redemocratização do Estado brasileiro na década de 1980, quando tivemos o advento de uma nova Constituição Federal, em 1988, que, de acordo com Sposito (2003) instaurou um novo ordenamento social voltado para uma consciência de direitos e cidadania.

Entre os anos de 1995 a 2005, foram implementados com abrangência nacional, para os jovens de 14 a 29 anos de idade, o Plano Nacional de Qualificação do Trabalhador (PLANFOR), Projeto Agente Jovem de Desenvolvimento Social e Humano, Projeto Soldado Cidadão, Programa Escola de Fábrica, Programa Nacional de Inclusão de Jovem (PROJOVEM) e Programa do Jovem Aprendiz. Estes buscam viabilizar através da formação e/ou qualificação profissional o acesso ao mercado de trabalho.

Pode-se dizer que as formas de execução dessas políticas públicas educacionais por meio desses programas e projetos aqui mencionados, partem do pressuposto de que a dificuldade para encontrar o primeiro emprego ou se reinserir no mercado está na falta de experiência, na baixa escolaridade, na falta de qualificação ou formação profissional dos jovens. Diante disso, apresentam duas vertentes de ações: aquelas que em médio prazo visam ao aumento da escolaridade do jovem, e a outra, que em curto prazo, por meio da qualificação e/ou formação profissional, promovam a inserção dos jovens no mercado de trabalho.

É preciso considerar algumas características desses programas e projetos, como a focalização, isto é, a prioridade no atendimento de jovens pobres como aqueles pertencentes às famílias com baixa renda per capita (de até meio salário ou um salário mínimo), a baixa escolaridade, a persistente fragmentação e desarticulação entre os programas e projetos, pois a maioria deles apresenta público-alvo e objetivos semelhantes, além de serem executados na mesma área territorial. Também, o caráter descentralizado de execução e a forte participação de ONGs no processo de educação e a descontinuidade dos programas, pois 
estes não preveem o encaminhamento nem de parcelas dos participantes ao mercado de trabalho quando do término de seu período de participação nas atividades do Programa.

Assim, este artigo tem por objetivo demonstrar ao longo deste estudo como as atividades da formação profissional dada pelo Programa do Jovem Aprendiz tiveram influências na escola regular. Isto porque uma das condições dadas como pré-requisitos para que o Jovem Aprendiz, filhos (as) da classe trabalhadora, participem do Programa sob a condição de aprendizagem, é de estarem matriculados no ensino fundamental, médio ou em curso de formação técnica.

Ao ser contrato como Aprendiz pela empresa, os Jovens acabam por desenvolver uma tripla jornada diária, ou seja, se comprometem em participar das aulas teóricas do Programa, de cumprir seu horário de atividade prática estabelecido pela empresa contratante e de frequentar o ensino regular ou técnico. Assumem precocemente responsabilidades de um adulto, o que acabam por abdicar do lazer, dos esportes e de outras atividades essenciais a sua vida, além de prejudicar o rendimento escolar deles.

Conforme a Lei de Diretrizes e Bases da Educação Nacional (LDB) de 1996, a faixa etária de 15 a 18 anos deveria estar regularmente matriculada na etapa final da educação básica. Desta forma, estariam se preparando para a vida adulta, e posteriormente, após concluírem seus estudos, é que estariam preparados para ingressar no mundo do trabalho. Assim, indagamos: Por que investir precocemente na formação profissional desses Jovens ao invés de primeiramente investir na Educação geral para depois prepará-los para enfrentar o mundo adulto? Por que saltar as fases que deveriam ser contempladas para o desenvolvimento psicossocial e profissional dos Jovens, para dotá-los de compromissos e responsabilidades de um adulto? Por que investir nesta política de formação profissional se ela causa impactos não positivos no ensino regular ou técnico destes Aprendizes?

Portanto, o que nos instiga a esta investigação é que aparentemente o Estado investe nesta formação para demonstrar para a sociedade de que está cumprindo com sua função social em propor políticas educacionais para os jovens objetivando formá-los para o mercado de trabalho. De tal modo, o Estado, 
ideologicamente, enfatiza de que a formação profissional dada pelo Programa propicia o ingresso e/ou manutenção destes no mercado de trabalho, e desta forma assegura por meio desta estratégia a manutenção do ideário neoliberal nas relações de aprendizagem e de produção, mesmo que esta prática educativa tenha impactos negativos para a vida social e educacional dos Jovens.

Metodologicamente, o objeto de estudo foi situado historicamente de acordo com os princípios e fundamentos do materialismo histórico dialético, levando em consideração a superestrutura do sistema capitalista e as condições com que esta política educacional foi sendo produzida e reproduzida pelo Estado em favor da hegemonia do sistema capitalista. Para tanto, priorizou-se uma abordagem qualitativa, utilizando como instrumentos entrevista semiestruturada por intermédio de um grupo focal, desenvolvidas com os Jovens Aprendizes. Estes foram os que tiveram o SENAC/MS como entidade responsável por thes oferecer a formação teórica profissional, no período de 2007 a 2009 e que foram contratados (efetivados) nas empresas no ano de 2008 a 2010. Participaram deste estudo onze Jovens Aprendizes, sendo quatro homens e sete mulheres, que tiveram sua formação prática em três empresas distintas. No momento da realização dessa técnica foi assinado pelos entrevistados um Termo de Consentimento Livre e Esclarecido, garantindo a privacidade e a confidencialidade das informações coletadas para a análise e publicação final do resultado da entrevista. Serão utilizados a terminologia Aprendiz 1, Aprendiz 2, Aprendiz 3, sucessivamente, quando nos referirmos aos Jovens, e nome fictício para designar as empresas, como: empresa Alfa, Beta e Gama. Os dados foram analisados a partir da técnica da análise do discurso, fazendo surgir às categorias que foram trabalhadas a partir das temáticas discutidas como instrumento de apreender como os Jovens Aprendizes, diante do contexto vivenciado por meio das atividades teóricas e práticas do Programa, conseguiam lidar e sustentar seu processo de aprendizagem no ensino regular de nível fundamental, médio ou técnico.

Visando atender o objetivo $\mathrm{e}$ as necessidades de exposição desta pesquisa, a seguir serão apresentados os conteúdos que fundamentam as seções da estrutura deste estudo e como serão tratados como partes integrantes do processo de investigação. 
Na seção I, faremos uma exposição sobre o que é e como se estrutura o Programa do Jovem Aprendiz com base na Lei № 10.097/2000 e no Decreto no $5.598 / 2005$, legislações que regulamentam tal Programa. Buscaremos demonstrar quem são os Jovens Aprendizes, como se estabelece o Programa nas empresas, como se processa as atividades teóricas e práticas que os jovens devem desenvolver e quais os direitos e obrigações dos aprendizes com as atividades teóricas e práticas do Programa. Na seção II, discutiremos sobre o trabalho precoce, educação e qualificação profissional, tendo por intuito demonstrar como o tratamento dado pelo Estado, principalmente a partir do final do século XX e início deste século XXI, sofreu as determinações do marco histórico do ideário neoliberal da atual conjuntura da sociedade capitalista em que a reestruturação produtiva e a flexibilização das relações sociais de trabalho se fazem presente. $\mathrm{E}$ na seção III, iremos demonstrar e analisar as implicações positivas e/ou negativas que as atividades teóricas e práticas do Programa do Jovem Aprendiz tiveram para os Aprendizes com relação à escola regular, no sentido de produzir e reproduzir através de suas falas e ações a ideologia que está por trás do processo de formação profissional posto pelo Estado para esta classe social.

Contudo, esperamos que os resultados apresentados neste estudo sejam relevantes para contribuir e subsidiar discussões entre pesquisadores e profissionais que lidam com a formação/qualificação profissional de jovens, e que possibilitem reflexões sobre as políticas públicas colocadas pelo Estado e como estas vem se manifestando diante das contradições engendradas na sociedade pelo capital.

\section{O Programa do Jovem Aprendiz}

Para um melhor entendimento sobre a estrutura do Programa do Jovem Aprendiz e como este vem sendo desenvolvido, convém ressaltar que 0 art. $2^{\circ}$ do Decreto $n^{\circ}$ 5.598/2005 determina que "o aprendiz é o maior de quatorze anos e menor de vinte e quatro anos que celebra contrato de aprendizagem, nos termos do art. 428 da Consolidação das Leis do Trabalho - CLT". Esse decreto ampliou a idade do aprendiz para a participação no Programa, uma vez que antes, pela Lei no 10.097/2000, era considerado aprendiz o adolescente de 14 a 18 anos. O 
referido Programa apresenta como pré-requisito que os candidatos ao trabalho sob a condição de aprendizagem, devem estar matriculados no Ensino Fundamental, Médio ou em um curso de formação técnica. Também, não podem ter tido nenhum tipo de registro em sua carteira de trabalho, ou seja, a participação nesse processo de aprendizagem deverá ser a sua primeira experiência profissional. $O$ contrato de aprendizagem é celebrado entre a empresa e o aprendiz, e, de acordo com o art. $8^{\circ}$ desse Decreto, entende-se que este:

[...] é o contrato de trabalho especial, ajustado por escrito e por prazo determinado não superior a dois anos, em que o empregador se compromete a assegurar ao aprendiz, inscrito em programa de aprendizagem, formação técnico-profissional metódica compatível com o seu desenvolvimento físico, moral e psicológico, e o aprendiz se compromete a executar com zelo e diligência as tarefas necessárias a essa formação (BRASIL, 2005, art. $\left.8^{\circ}\right)$.

Conforme as exigências da CLT, especificamente no que se refere ao trabalho do aprendiz, esse contrato de aprendizagem deve conter, expressamente, qual o curso de formação profissional que o aprendiz está matriculado, a jornada de trabalho diária ou semanal, a definição da quantidade de aulas teóricas, as horas de trabalho que fazem na empresa, a remuneração mensal e o início e término do contrato.

Por se tratar de um programa de formação técnico-profissional metódica, o art. $6^{\circ}$ do Decreto $n^{0}$ 5.598/2005, que regulamenta tal programa, define por "formação técnico-profissional metódica para os efeitos do contrato de aprendizagem as atividades teóricas e práticas, metodicamente organizadas em tarefas de complexidade progressiva desenvolvidas no ambiente de trabalho". Ou seja, o processo educacional e metodológico é caracterizado concomitantemente entre atividades teóricas e práticas, dentro de um começo, meio e fim, visando à profissionalização do aprendiz como um meio de proporcionar a sua continuidade no mercado de trabalho. Porém, geralmente não é isto o que vem acontecendo, pois os aprendizes exercem suas atividades na empresa de acordo com o que os demais funcionários querem que eles façam. Tal justificativa se dá em função das entrevistas realizadas com os Jovens Aprendizes, sendo esta uma condição para que eles venham a ser contratados como funcionários da empresa. 
Para a empresa a obrigação é que abra vagas para contratação dos aprendizes na proporção de 5\% a 15\% do total de trabalhadores empregados, em funções que demandem formação profissional. De acordo com o art. 10 do Decreto $n^{\circ}$ 5.598/05, deverá ser consultada a Classificação Brasileira de Ocupações (CBO), elaborada pelo Ministério do Trabalho e Emprego para saber quais são estas funções. Porém o $\S 1^{\circ}$ do mencionado artigo, relata que ficam excluídas as funções que demandem formação profissional, a habilitação profissional de nível técnico ou superior, e as funções de gerência, cargos de direção e de confiança. Observamos que as funções que demandam formação profissional estão voltadas para o trabalho técnico, e assim, é neste contexto que os aprendizes serão formados dentro da empresa, para executarem funções específicas e rotineiras.

O Jovem Aprendiz participará do programa por um período de no máximo dois anos, para aprender uma profissão e ter uma oportunidade de emprego e renda. Essa formação técnico-profissional deve ser oferecida por concomitância entre as atividades teóricas e práticas, organizadas em tarefas de complexidade progressiva. Sendo que as atividades práticas são exercidas dentro da empresa que contratou o jovem como aprendiz e a formação teórica fica sob a responsabilidade das instituições pertencentes ao Serviço Nacional de Aprendizagem, sendo estes o SENAI, SENAC, SENAR, SENAT e o SESCOOP; além das escolas técnicas federais de educação e ONGs, sendo que essas últimas devem estar devidamente registradas no Conselho Municipal de Desenvolvimento da Criança e do Adolescente, conforme prevê a legislação.

Quando da contratação do Jovem Aprendiz pela empresa, é celebrado um contrato especial de trabalho por tempo determinado entre ele e a empresa contratante, pelo qual é garantido ao contratado o salário mínimo hora. Esse Programa é implementado pelo Ministério do Trabalho e Emprego e compete às Superintendências Regionais do Trabalho e Emprego a orientação e fiscalização nos Estados.

Ao ser contratado como aprendiz pela empresa, o jovem deve se comprometer com as atividades propostas pelo programa, ou seja, tanto participar das aulas teóricas, quanto cumprir seu horário de atividade prática estabelecido pela empresa contratante. A duração do trabalho do Jovem Aprendiz não poderá 
exceder a seis horas diárias, já computadas as horas teóricas das aulas e as atividades práticas desenvolvidas na empresa que o contratou, conforme os arts.

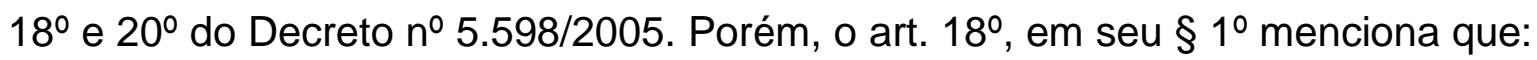
"o limite previsto no caput deste artigo poderá ser de até oito horas diárias para os aprendizes que já tenham concluído o ensino fundamental, se nelas forem computadas as horas destinadas à aprendizagem teórica".

Para tanto, é celebrado um contrato especial de trabalho entre a empresa contratante e o Jovem Aprendiz, e a este será garantido todos os direitos trabalhistas no que se refere ao trabalho do aprendiz, como vale-transporte, salário mínimo-hora (computadas as horas das aulas teóricas), descanso semanal remunerado e feriados, ter suas férias coincididas com as férias escolares (apenas para os menores de 18 anos), afastamento por ocasião de licença maternidade ou acidente de trabalho, e recolhimento do Fundo de Garantia do Tempo de Serviço (FGTS). No entanto, esse recolhimento corresponde a $2 \%$ da remuneração paga ou devida ao aprendiz, de acordo com o art. 24 do Decreto $5.598 / 2005$, no qual se aplica o artigo $15, \S 7^{\circ}$ da Lei ํo 8.036 , de 11 de maio de 1990 , relatando que "os contratos de aprendizagem terão a alíquota a que se refere o caput deste artigo reduzido para dois por cento". Diante deste exposto, observamos que essa alíquota no recolhimento de $2 \%$ no FGTS do Jovem Aprendiz é uma forma de o Estado incentivar as empresas a cumprir com a quota estabelecida na Lei do Jovem Aprendiz, e, desta forma, o Estado continua a favorecer a dinamização do capital, já que quem lucra com essa redução é o próprio empresário, e quem sai prejudicado é o jovem trabalhador aprendiz, filhos (as) da classe trabalhadora.

Percebemos que os Jovens Aprendizes possuem os mesmos direitos trabalhistas e previdenciários dos demais empregados, porém com uma redução na alíquota de recolhimento do FGTS, e o seu horário de trabalho é especial, para não prejudicar os estudos. Desta forma, os jovens que estudam pela manhã devem ter a parte teórica do programa à tarde e a prática, à noite, ou parte prática à tarde e parte teórica à noite. Como a oferta de trabalho na empresa é geralmente nos períodos da manhã e tarde, a maioria dos aprendizes acabam sendo obrigados a estudarem à noite, o que acaba por causar implicações com o 
processo de aprendizagem na escola regular, conforme averiguado nos discursos dos jovens.

\section{Trabalho precoce, educação e qualificação profissional}

Iniciamos esta discussão sobre trabalho precoce e formação/qualificação profissional voltada para os jovens pobres, pela atual conjuntura da sociedade capitalista, com a intenção de mostrarmos como o tratamento dado pelo Estado ao ensino profissional, no final do século XX e início deste, século XXI, sofreu as determinações do marco histórico do ideário neoliberal desta atual fase da sociedade capitalista, marcada pelo crescimento do setor de serviços, pela reestruturação produtiva e flexibilização das relações de trabalho.

A década de 1980 foi palco de significativas mudanças no sistema político brasileiro, em função da redemocratização do Estado em 1985, na medida em que iniciamos a construção de um Estado civil e democrático. Isto porque saímos de um longo período de ditadura militar, centrado em um Estado autoritário, cujas ações coercitivas das forças militares, estavam voltadas para atender a burguesia industrial nacional e internacional.

No entanto, percebe-se que a transição desse governo ditatorial para um governo democrático, se deu de maneira lenta e gradual, em detrimento das lutas e dos movimentos sociais voltados para a reinstauração da liberdade democrática de forma rápida. Ao tanto que nos primeiros três anos do regime político democrático, foi promulgada em 1988, pelo Presidente da República, José Sarney, a Constituição Federal da República, e esta trouxe mudanças com relação à Educação, definindo-a como competência da União, dos Estados, do Distrito Federal e dos Municípios de "proporcionar os meios de acesso à cultura, à educação e à ciência" (Constituição Federal de 1988, art.23, V).

Em seu Capítulo II, que trata Dos Direitos Sociais, o artigo 6ํㅡ, assegura que "São direitos sociais, a educação, a saúde, o trabalho, a moradia, o lazer, a segurança, a previdência social, a proteção a maternidade e a infância, a assistências aos desamparados, na forma desta Constituição". Observa-se que no que se refere à educação e ao trabalho, assegurados pela referida Constituição, bem como o dever do Estado garantir o acesso da sociedade a 
estes direitos, resultou, aproximadamente, doze anos após a promulgação desta Constituição Federal, na implementação do Programa do Jovem Aprendiz, objeto deste estudo.

Através deste programa o governo proporciona a uma pequena parcela de jovens da classe trabalhadora, já que o programa não consegue abarcar a toda população de jovens brasileiros, com idade entre 14 a 24 anos, a participar por um determinado período de tempo de uma formação profissional como forma de prepará-lo para o ingresso no mercado de trabalho. É relevante destacar que esta formação está direcionada, praticamente, para atender ao setor terciário da economia, que engloba as atividades de prestação de serviços e comercialização de produtos, em função deste ser o setor que mais cresce na economia brasileira desde o final dos anos de 1980 (POCHMANN, 2002).

Porém, no que se refere à educação, estes jovens deveriam estar devidamente matriculados no ensino regular, conforme prevê a LDB de 1996, mas não é isto que se revela, pois muitos deles, que deveriam estar dentro da escola, se encontram fora dela. Outro aspecto a ser considerado com relação ao Programa do Jovem Aprendiz, é que os jovens que participam desta formação profissional, deveriam estar devidamente matriculados no ensino fundamental e médio e após a conclusão deste, prosseguir seus estudos para a educação de nível superior, para posteriormente entrar para o mundo do trabalho. Portanto, através deste contexto, notamos que o Estado ainda não conseguiu assegurar os direitos dos jovens, especialmente, no que se refere à educação e ao trabalho, conforme garantido na Constituição Federal.

Retornando ao marco histórico desta Constituição, destacamos que dois anos após a sua promulgação foi também promulgado pelo Estado, em 1990, na gestão do Presidente da República Fernando Collor, o Estatuto da Criança e do Adolescente (ECA). Este, além de garantir direitos e proteção aos jovens, tratou também da educação, em especial da educação profissional, conforme o título I, artigo 4:

É dever da família, da comunidade, da sociedade em geral e do poder público assegurar, com absoluta prioridade, a efetivação dos direitos referentes à vida, à saúde, à alimentação, à educação, ao esporte, ao lazer, à profissionalização, à cultura, à dignidade, ao respeito, à liberdade e à convivência familiar e comunitária (ECA, 1990, art. $\left.4^{\circ}\right)$. 
No que se refere à Educação, o Capítulo IV, artigo 53, deste estatuto, assegura que "a criança e o adolescente têm direito à educação, visando ao pleno desenvolvimento de sua pessoa, preparo para o exercício da cidadania e qualificação para o trabalho [...]". E no que se refere à idade para o trabalho, o Capítulo V, que trata do Direito à Profissionalização e à Proteção no Trabalho, art. 60, adverte que "É proibido qualquer trabalho a menores de quatorze anos de idade, salvo na condição de aprendiz". Compreendemos então, que o trabalho destes jovens, filhos (as) da classe trabalhadora, que participam destas formações/capacitações deveria ter um caráter substancialmente educativo e de formação humana, como referido no $\S 1^{\circ}$ do art.68, deste mesmo Capítulo, que "entende-se por trabalho educativo a atividade laboral em que as exigências pedagógicas relativas ao desenvolvimento pessoal e social do educando prevalecem sobre o aspecto produtivo".

Com base no exposto, abarcamos a importância com que o Estado tratou a questão da formação/capacitação profissional, bem como favoreceu meios de proteger e garantir direitos aos jovens brasileiros, destacados pela CF de $1988 \mathrm{e}$ pelo ECA de 1990. Porém, estes ainda foram insuficientes para proporcionar uma educação pelo trabalho e para a vida, direcionados para o desenvolvimento de uma consciência crítica do educando. Isto, em função desta educação está sendo sempre reestruturada em conformidade com os interesses do capital, e, portanto, submetida ao ideário do estado neoliberal e a reestruturação produtiva já que "[...] o capital constituiu uma poderosíssima estrutura totalizante de organização e controle do metabolismo societal, à qual todos, inclusive os seres humanos, devem se adaptar" (ANTUNES, 2009, p. 25).

Assim, a qualificação profissional posta pelo Estado para os jovens, filhos (as) da classe trabalhadora, não contempla uma formação ampla e sistemática com o desenvolvimento de uma consciência social crítica do educando, no intuito de thes proporcionar que sejam sujeitos que compreendem o sentido real do trabalho que desenvolvem, bem como as transformações relacionadas a este. Reduz a uma formação direcionada para que os jovens aprendam a serem trabalhadores multifuncionais e com capacidade de se adaptarem rapidamente e constantemente a qualquer condição de realização do trabalho, já que "a 
produção se estrutura num processo produtivo flexível, que possibilita ao operário operar simultaneamente várias máquinas, alterando-se a relação homem/máquina na qual se baseava o taylorismo/fordismo" (ANTUNES, 2009, p. 56).

A predominância destes interesses capitalistas na educação profissional, não é um fenômeno recente nas questões políticas e econômicas da agenda governamental, pois, historicamente, o Estado sempre atuou e vem atuando a favor da classe detentora dos meios de produção, ou seja, a favor do capital. E, conforme o movimento dialético do marxismo: negação, conservação e ascensão, compreendemos que ainda não aconteceu a completude deste movimento, já que o capital nunca foi negado, mas sim, sempre conservado e reorganizado pelo favorecimento político e econômico do Estado (KRAPIVINE, 1986).

Como a base ideológica que permeia a sociedade capitalista foi conservada, pois nada foi alterado na materialidade, o que vimos experimentando são mudanças nos meios e recursos empregados para a expansão do capital. Desta forma, a formação para o trabalho continua voltada para treinar e formar o jovem especificamente para atender as exigências da reestruturação dos meios de produção, que vão se reorganizando para preservar a conservação material da estrutura capitalista na sociedade. Para Krapivine (1986) esta concepção deve ser entendida enquanto um processo de estruturação, no qual os fatos devem ser racionalmente compreendidos a partir do lugar e das relações que ocupam e que se estabelece com o todo, pois a totalidade aparece como categoria de análise do real, significando que o "[...] conhecimento de fatos e conjunto de fatos vem a ser conhecimento do lugar que eles ocupam na totalidade do próprio real" (KOSIK, 1995, p. 41).

Para superar os reducionismos das concepções empiristas e idealistas presentes na sociedade de classe, há necessidade de articular dialeticamente os aspectos externos com os internos, levando em consideração a relação do sujeito com a sociedade no qual está inserido. O que nos revela o fato que estes ao produzirem e reproduzirem a sua realidade social, são também e ao mesmo tempo, produzidos e reproduzidos por esta realidade, conservando assim, a hegemonia que o capital vai estabelecendo.

Com base no exposto, convém ressaltar que concomitantemente ao processo de redemocratização do Estado Brasileiro na década de 1980, o mundo 
capitalista, principalmente os países que controlam a economia mundial, como por exemplo, os Estados Unidos, Inglaterra, Japão, França, estavam incrementando a globalização de suas economias. Esta se deveu ao desenvolvimento da tecnologia, que propiciou a interligação e a movimentação do capital financeiro de suas empresas para qualquer parte do mundo, dando início a Terceira Revolução Industrial e Tecnológica. Ideologicamente esta vem sendo caracterizada como uma nova sociedade, na qual as principais exigências para o trabalhador são o domínio da informação e do conhecimento de acordo com as necessidades do mercado. Destas condições decorreram medidas de liberalização e desregulamentação das economias nacionais, conforme destaca lanni (2008), ampliando a mobilidade do capital e do trabalho no cenário econômico mundial, o que levou à transformação do mundo em um só mercado. Com estas transformações econômicas tornando o mundo em um só mercado, abriu-se um período de incertezas e questionamentos sobre o padrão sistêmico de integração social, que vem se materializando com o Estado neoliberal. De acordo com Frigotto (1995):

A tese neoliberal postula a retirada do estado da economia - a ideia do Estado Mínimo -; a restrição dos ganhos de produtividade e garantias de emprego e estabilidade de emprego; a volta das leis de mercado sem restrições; o aumento das taxas de juros para aumentar a poupança e arrefecer o consumo; a diminuição dos impostos sobre o capital e a diminuição dos gastos com receitas públicas e, consequentemente, dos investimentos em políticas sociais. (FRIGOTTO, 1995, p.80-81).

Desse modo, o Estado assume a responsabilidade de preparar os jovens para atender o mercado de trabalho através dos programas e projetos de formação, capacitação e requalificação profissional. Estes foram institucionalizados por meio das reformas educacionais, realizadas pelo Estado Brasileiro, principalmente a partir do primeiro governo de Fernando Henrique Cardoso (1995-2002), para atender a necessidade da flexibilização do trabalho que o capital impunha.

A política de educação profissional do governo de FHC não se resumiu ao ensino técnico. Ela abrangeu ações voltadas para a qualificação e a requalificação profissional, desviando a atenção da sociedade das causas reais do desemprego para a 
responsabilidade dos próprios trabalhadores pela condição de desempregados ou vulneráveis ao desemprego. Esse ideário teve nas noções de 'empregabilidade' e 'competências' um importante aporte ideológico, justificando, dentre outras iniciativas, projetos fragmentados e aligeirados de formação profissional, associados aos princípios de flexibilidade dos currículos e da própria formação. (FRIGOTTO, CIAVATTA, RAMOS, 2005, p.13).

Nestas circunstâncias, a educação assume um papel fundamental dentro da dimensão ideológica, ajustando-se para transmitir os conhecimentos necessários para a conservação do sistema capitalista, através da qualificação e requalificação profissional apresentada como um mecanismo para garantir a empregabilidade. A educação acaba por se reduzir em diplomas para balizarem a disputa por uma vaga de emprego, onde quem tem mais capital humano, tem a vantagem sobre os concorrentes. A formação para o trabalho com as novas tecnologias e equipamentos cada vez mais sofisticados tem se tornado objeto de negociação entre o capital e o Estado, e de acordo com Neves (2007) "a política educacional neoliberal focaliza a ação direta do Estado [...] de sua participação nos programas de formação profissional [...]" (NEVES, 2007, p.213).

Compreendemos a atuação do Estado com relação aos programas de formação e qualificação profissional. Porém, comprovamos que este seu dever de legislar e oferecer a educação, não contempla a promoção do desenvolvimento da consciência individual e/ou de classe para os jovens, e nem se preocupa com as implicações que têm ou poderão ter no processo de aprendizagem do ensino regular ou técnico que os Jovens Aprendizes estão matriculados.

Corrobora a nossa argumentação o fato de que a formação proposta pelos programas e projetos de educação profissional para os jovens se destinarem ao desenvolvimento de habilidades específicas, ou seja, os Jovens Aprendizes são formados para desenvolverem trabalhos com baixo requisito técnico e sem domínio da ciência ou das condições de trabalho ou produção, e desta maneira, continuam contribuindo, através da venda da sua força de trabalho, para o fortalecimento e a conservação do capital, pois toda venda de força de trabalho, seja para trabalho técnico ou complexo, contribui para a expansão do sistema capitalista.

Além disto, os programas e projetos de formação/capacitação profissional estão voltados para a preparação precoce para o trabalho, o que torna a 
formação, além de aligeirada e fragmentada, preleções ideológicas de que esta propiciará conhecimentos para que os Jovens estejam aptos para ingressarem no mercado de trabalho. Sob tais condições, o Estado aliado ao capital, difunde-se as ideias neoliberais, o que acaba por dificultar a busca pela educação geral, já que conforme veremos nos discursos abaixo, há implicações não positivas na vida escolar e particular dos Jovens, já que estes desenvolvem uma tripla jornada diariamente, o que prejudica o seu processo de aprendizagem no ensino regular.

\section{As influências que as atividades do Programa do Jovem Aprendiz tiveram na escola regular: Falam os Jovens Aprendizes}

Nesta categoria analisaremos as influências positivas e/ou negativas que os jovens tiveram na escola após entrarem para o Programa do Jovem Aprendiz, pois conforme já evidenciado, além de participarem das atividades teóricas e práticas requeridas pelo programa, é pré-requisito que esses jovens estejam matriculados no ensino fundamental, médio ou em um curso de formação técnica.

Quando questionamos aos jovens se houve alguma influência positiva no seu rendimento escolar após entrarem para o Programa, tivemos os seguintes relatos:

Para mim melhorou a ter mais organização com as coisas, dar prioridade, ter disciplina. (Aprendiz 1- empresa Alfa).

A gente aprende a usar melhor o tempo né?! Trabalhando. Porque, às vezes, quando você estudava de manhã, você chegava em casa, você ia estudar, lógico que não, ia dormir, [...] então assim, usar melhor o tempo. Eu não tive nenhum problema não de rendimento escolar durante o Programa. Minhas notas todas foram boas. Final de semana e, também, tinha final de semana para estudar, então não tinha problema não! Nenhum problema. (Aprendiz 2- empresa Alfa).

Eu acho que raciocina mais rápido. Assim né?! Porque você não tem mais o tempo que você tinha para estudar. Então você presta mais atenção na aula, porque aquele é o tempo que você tem, porque você não vai ter um tempo a tarde, a noite para você conseguir ler depois. Para mim, eu não posso falar que em nada influenciou na escola por causa do programa. Eu sempre dava um jeito de estudar final de semana ou na escola mesmo, quando não tava tendo aula muito importante, estudava para outra, né!? (Aprendiz 3 - empresa Alfa). 
No começo foi muito difícil negociar escola, trabalho, tudo. A rotina muda completamente. [...] a gente fica com receio de fazer as coisas. Será que vai dar certo? Será que não? Mas, Graças a Deus, eu não tive problema nenhum quanto a isso. (Aprendiz 4empresa Alfa).

$\mathrm{Na}$ escola continuô a mesma coisa. Como eu já falei, anteriormente eu até trabalhava, então, eu sempre estudei a noite, a partir do primeiro ano eu já estudei a noite, então pra mim, meu cotidiano não mudou nada. No colégio minhas notas continuaram altas, não mudou nada não. Não afetou nada. (Aprendiz 6 empresa Beta)

O Programa ajudô na escola. Questão de português, história, matemática [...] tinha coisa que nós aprendíamos no curso e na sala de aula não. (Aprendiz 8 - empresa Gama)

No serviço, [...] não me atrapalhou, [...] é porque se precisasse de fazer um trabalho, entendeu? É, dava um tempinho ali e fazia, [ ] tipo assim, não era uma coisa, precisa, eu ia, 5 minutinhos fazia, rapidinho, né?! (Aprendiz 10 - empresa Gama)

Pra mim, me ajudou um pouquinho na parte de escrita, foi o que mais me ajudou, a parte de texto. Até foi numa época de vestibular da Federal, ai todo ano davam tipo dissertação, argumentação, dissertativa, né?! Elaborar carta, memorando e como eu aprendi isso no curso, isso me ajudou no meu desempenho. E, em relação aqui, a escola não atrapalhou porque eu já tinha terminado, né?! (Aprendiz 11 - empresa Gama)

Com base nesses discursos, percebemos que a influência positiva que o Programa teve com a escola regular, está direcionada para a questão de planejamento, ou seja, o jovem teve que se organizar e planejar para dar conta de frequentar a escola e participar das atividades teóricas e prática do Programa, conforme destacado neste discurso:

[...] eu fazia curso na quinta, sexta e sábado à tarde. Segunda, terça e quarta eu ficava o dia todo na empresa, quinta e sexta na parte da manhã, e eu estudava a noite, então aquela correria. Ás vezes, eu nem tinha ficado com a minha mãe direito, mas, enfim, foi corrido, mas valeu a pena. (Aprendiz 10 - empresa Gama)

Constatamos que esses Jovens utilizaram estratégias, como por exemplo, usar melhor o seu tempo para não se prejudicarem nas atividades da escola. Começaram a utilizar outros instrumentos, como prestar mais atenção durante as aulas, estudarem nos finais de semana e se organizarem para darem conta de todas as suas atividades. No entanto, entendemos que os compromissos dos 
jovens assumidos com o Programa do Jovem Aprendiz acabam é por dotá-los de responsabilidades como se fossem adultos, saltando fases importantes de sua vida, que deveriam, primeiramente, ser contempladas para o desenvolvimento psicossocial desse indivíduo. Acabam se abdicando do lazer e do descanso do final de semana para se dedicarem aos seus estudos, já que durante a semana estão comprometidos com as atividades do Programa, já que "o indivíduo moderno se vê num mundo logicamente planejado e programado para fazê-lo funcionar, independentemente de seus desejos e motivos pessoais" (CRUZ, 1999, p.177).

Por sua vez, ao perguntarmos aos Jovens se houve alguma influência negativa no seu rendimento escolar, tivemos as seguintes colocações:

[...] tinha professor que dava uma atividade no primeiro tempo e depois não queria de dar no segundo, mesmo sabendo que você chegou atrasado não porque você quis, porque tem um motivo, tava trabalhando como aprendiz. Tem dia que não dá para sair no horário do serviço. Eu gostava muito de ler e eu parei um pouco de ler por causa do cansaço, né!? e essa correria (Aprendiz 2empresa Alfa).

[...] as minhas faltas aumentaram muito, devido eu estudava de manhã, então, de manhã parece que é uma rotina muito maior para você ir pra escola e aí eu mudei para noite, as minhas faltas aumentaram muito. Também porque eu já tinha trabalhado o dia todo e, às vezes, ia para casa e ficava com preguiça de voltar para escola. E chegava atrasada também. Eu dependia de carona [...] porque eu estava longe da minha casa. Mas, só em questão de faltas e chegar atrasada. Mas chegar atrasada não era uma rotina, era às vezes. Mas falta, aumentou bastante (Aprendiz 3 empresa Alfa).

Assim, em questão das notas, algumas caíram depois que comecei como aprendiz. Sempre minha média era de sete para cima, nunca abaixo disso. Aí, depois que eu comecei trabalhar, começou a ser seis, sete, mas nunca abaixo da média, assim, eu mesmo me policiava para estudar, para não ir com seis. Tipo assim, para mim, eu não estava satisfeita que eu posso ir com seis, só de sete para cima. Às vezes, até com sete eu não ficava satisfeita. Ainda ficava meio assim. Mas a questão das faltas, também chegava muito no segundo tempo. Eu estava muito cansada, vô em casa tomar um banho, depois eu vou para escola (Aprendiz 4- empresa Alfa).

Não havia tempo pra, pra fazer trabalho, tarefas. Né?! Porque, ainda mais na recepção, não tem como, como você fazer trabalho, toda hora o telefone toca, [...] os beneficiários chega. Igual 
português, tirava 7, 8, depois fui pra 5. (Aprendiz 8 - empresa Gama)

Na escola o meu cotidiano mudou. Porque eu sempre estudei durante o dia né?! Ai, então, tive que mudar pra noite e, assim, saia do serviço direto pra escola e, às vezes, tava cansada, às vezes faltava, a gente falta, entendeu? Não tinha tempo pra fazer trabalho, nem tarefa, nem nada, o tempo era curto. Quando tinha prova, às vezes, eu chegava em casa e estudava, mas nem sempre eu conseguia, ou então tentava chegar mais cedo na escola e ficava lá estudando até começar a aula. (Aprendiz 6 empresa Beta)

Observa-se que chegar atrasado à escola foi um problema praticamente central manifestado nos discursos dos jovens, seguido de faltar aulas, perder atividades na escola, cansaço e redução de notas nas disciplinas. Abarcamos o quanto este programa influencia negativamente no rendimento escolar dos alunos, pois conciliar estudo com as obrigações do programa não é uma tarefa simples, conforme é idealizado pelo discurso neoliberal e que se manifesta nessa aprendizagem profissional, no qual os jovens devem desde cedo se qualificarem para ingressarem no mercado de trabalho. Estudar e trabalhar exige um esforço físico-mental, a julgar pelos discursos manifestados neste estudo, o que causa prejuízos com relação à escolarização do jovem, pois:

“[...] as concepções de educação e capacitação para o trabalho que residem esses programas estão impregnadas por uma lógica de formação para a subalternidade, sem romper com os lugares sociais que estão inseridos para eles" (CASSAB, 2001, p.95).

A formação profissional presente no Programa do Jovem Aprendiz se manifesta como uma educação para o trabalho, objetivando apenas a aquisição de competências para o mundo laboral, e não uma educação pelo trabalho, voltada para a concepção de trabalho como princípio educativo. E, muito menos, uma formação no qual os jovens pudessem negociar trabalho e estudo sem que fossem prejudicados. O que esperávamos é que o trabalho, conforme concebido sobre a condição de aprendizagem, que é permitido legalmente pela Lei do Jovem Aprendiz, não os prejudicasse nos estudos. No entanto, os discursos manifestados pelos jovens revelam outra realidade, pois até não sair do trabalho na hora em que termina o seu expediente e consequentemente chegar atrasado à 
escola foi aparentemente explicitado por um aprendiz "Tem dia que não dá para sair no horário do serviço" (Aprendiz 2- empresa Alfa).

Convém ressaltar, o quanto o trabalho desses jovens é benéfico para a empresa no sentido da extração da mais-valia sobre o valor pago pelas horas de trabalho e a quantidade de horas trabalhadas. Também se torna benéfico no sentido da empresa formar esses aprendizes de acordo com as suas necessidades, ou seja, de encontro com as determinantes hegemônicas postas pelo mercado de trabalho, no qual exige um trabalhador flexível e multifuncional para saber lidar com as incertezas do sistema produtivo. Nesse contexto é que sobressai o Estado neoliberal, caracterizado por uma política econômica baseada na competitividade do mercado, sustentando os interesses intercapitalistas por meio da manutenção da taxa de lucro. Entende-se que "é no contexto do globalismo que o liberalismo se transfigura em neoliberalismo" (IANNI, 2008, p.217), articulando ideologicamente os interesses da classe dominante em âmbito mundial, como apreendido na inter-relação entre trabalho e educação do Programa do Jovem Aprendiz.

Por sua vez, a educação que deveria conscientizar para a vida, para transformar a realidade por meio do ideal da emancipação humana, acaba por se tornar em um objeto negociável entre os que compram e os que vendem a força de trabalho. Desse modo, deixa de ser um processo extenso por meio do qual se transmite uma cultura para quem está sendo educado, não uma cultura determinada pela sua condição de classe social, mas sim uma cultura no sentido amplo e significativo da palavra. Por isso, concordamos que a educação formal pode e deve abarcar a educação profissional, uma vez que:

[...] todas as dimensões da educação podem ser reunidas. Dessa forma, os princípios orientadores da educação formal devem ser desatados do seu tegumento da lógica do capital, de imposição de conformidade, e em vez disso mover-se em uma direção a um intercâmbio ativo e efetivo com práticas educacionais mais abrangentes [...] (MÉSZÁROS, 2005, p.58).

Os estudos e a continuidade destes pelos aprendizes, na perspectiva da Lei do Jovem Aprendiz, não parecem ter tanta relevância, poia a própria CLT que rege essa Lei, deixa transparecer tal visão, quando considera que o trabalho na condição de aprendizagem para os jovens que ainda não concluíram o Ensino 
Fundamental não pode exceder seis horas diárias, computando as horas destinadas às atividades teóricas e práticas, porém, para os que já concluíram esse ensino, e estão frequentando o Ensino Médio ou um curso de formação técnica, esse limite se amplia para até oito horas diárias. Por meio dessa ampliação de horas é que compreendemos como essa aprendizagem profissional prevalece sobre a escola regular, pois ao invés de manter as mesmas horas de atividades teóricas e práticas destinadas para todos os Jovens, independente da sua escolaridade, expande as horas para os demais e estas são computadas nas atividades práticas. Desta forma, precariza a relação desse Jovem com os seus estudos, conforme manifestado pelos discursos apreendidos, como também não o proporciona que sua escolarização se expanda de maneira eficiente.

\section{Considerações Finais}

Buscamos tecer ao longo deste estudo, considerações conclusivas acerca das implicações estabelecidas entre o processo de formação profissional do Programa do Jovem Aprendiz com o processo de aprendizagem no ensino regular ou técnico dos Jovens que participam do Programa.

Considerando a totalidade em que se insere o objeto analisado, procuramos situá-los historicamente de acordo com a lógica do mercado de trabalho, da complexidade das relações de produção e do neoliberalismo. Para isto, foi necessária uma análise das relações entre trabalho e educação que constituem o processo de formação profissional do programa.

Tomamos a educação como uma instituição social que no capitalismo constitui como um conjunto de determinações e funcionalidades vitais que medeiam à reprodução do capital, ao preparar os indivíduos apenas para as relações sociais de trabalho que vão se constituindo entre a classe que vende sua força de trabalho e a que compra o trabalho desses indivíduos, sem se preocupar com as influências que esta formação tem na vida escolar e pessoal destes Jovens. Concordamos com Mészáros (2005), quando nos mostra que a educação se tornou um instrumento da sociedade capitalista, no qual o conhecimento que se transfere diz respeito às informações necessárias para o processo produtivo e para a manutenção do seu posto de trabalho. 
O que se pode compreender com base na discussão realizada neste estudo, é que a formação profissional dada pelo Programa do Jovem Aprendiz contribui para a reprodução da sociedade de classe, induzindo nesse jovem uma internalização passiva das condições impostas pela hegemonia da classe dominante. Esta formação não possibilita o desenvolvimento de uma consciência crítica sobre o mundo do trabalho, se reduz a um processo, que na verdade incrementa a reprodução do capital, ao mesmo tempo, em que não possibilita uma inter-relação entre a aprendizagem do Programa com o ensino regular.

Diante dessa problemática, reconhecemos o tamanho dos problemas sociais que devem ser enfrentados no país, especialmente pelas particularidades expostas por meio desta pesquisa. Assim, o processo de formação profissional, posto pelo Estado através da Lei do Jovem Aprendiz, está longe de apontar para um caminho de transformação da relação trabalho e educação. Até porque, pelo já exposto neste estudo, a relação desse Jovem Aprendiz com a escola regular teve muito mais implicações negativas do que positivas, já que as notas das disciplinas reduziram, houve problemas com falta, chegar atrasado na escola pela incompatibilidade do horário de saída do trabalho, não entregar trabalhos, falta de tempo para estudar, mudança de turno escolar, dentre outros aspectos semelhantes.

Acreditamos que é preciso persistir na construção de um programa que proporcione aos jovens um entendimento amplo sobre a esfera do mundo do trabalho e que, ao mesmo tempo, consiga relacionar os aspectos da formação escolar com o trabalho, pois de nada adianta, termos diversos programas e ações destinadas a essa classe da população brasileira, se eles não conseguem fazer com que os jovens compreendam, historicamente, o que está por trás das verdadeiras raízes estabelecidas entre os que compram e os que vendem a força de trabalho.

\section{Referências}

ANTUNES, Ricardo. Os Sentidos do Trabalho: ensaio sobre a afirmação e a negação do trabalho. São Paulo, SP. 2ª ed. Boitempo, 2009.

BRASIL. Constituição da República Federativa do Brasil de 1988. Executivo. Disponível

em: 
http://www.planalto.gov.br/ccivil_03/constituicao/constitui\%C3\%A7ao.htm Acesso em: 23 de setembro de 2010.

. Decreto $\mathrm{n}^{\circ}$ 5.598, de $1^{\circ}$ de dezembro de 2005. Regulamenta a contratação de aprendizes e dá outras providências. Disponível em: http://www.planalto.gov.br/ccivil_03/_Ato2004-2006/2005/Decreto/D5598.htm Acesso em: 08 de setembro de 2009

. Lei oㅜ 10.097, de 19 de dezembro de 2000. Lei do Jovem Aprendiz. Altera dispositivos da Consolidação das Leis do Trabalho - CLT, aprovada pelo Decreto-Lei $\mathrm{n}^{\circ} 5.452$ de $1^{\circ}$ ㄹ de Maio de 1943. Disponível em: http://www.planalto.gov.br/ccivil_03/leis/L10097.htm Acesso em: 08 de agosto de 2009.

. Lei no 8.069, de 13 de julho de 1990. Dispõe sobre o Estatuto da $\overline{C r i a n c ̧ a} e$ do Adolescente e dá outras providências. Executivo, DF, 1990. Disponível em: http://www.planalto.gov.br/ccivil_03/leis/L8069.htm Acesso em: 15 de outubro de 2010.

CASSAB, Maria Aparecida Tardin. Jovens pobres e o futuro: a construção da subjetividade na instabilidade e incerteza. Niterói: Intertext, 2001.

CRUZ. Roberto Moraes. Formação Profissional e formação humana: os (des) caminhos da relação homem-trabalho na modernidade. In: AUED, B. W. (Org.) Educação para o (des)emprego. Petrópolis, RJ: Vozes, 1999.

FRIGOTTO, Gaudêncio. Educação e a Crise do Capitalismo Real. São Paulo: Cortez, 1995.

CIAVATTA, Maria. RAMOS, Marise. A Gênese do Decreto № 5.514/2004: um debate do contexto controverso da democracia restrita. In: TRABALHO NECESSÁRIO. Revista Eletrônica do Neddate, Disponível em http://www.uff.br/trabalhonecessario/MMGTN3.htm, 2005.

IANNI, Octavio. A Era do Globalismo. 10ª ed. Petrópolis - RJ. Vozes, 2008.

KOSIK, Karel. Dialética do concreto. 3. ed. Tradução de Célia Neves e Alderico Toríbio. Rio de Janeiro: Paz e Terra, 1995.

KRAPIVINE, V. O que é materialismo dialético? Moscou, Edições Progresso, 1986.

MÉSZÁROS, István. A Educação para além do capital. Trad. Isa. Tavares. São Paulo: Boitempo, 2005.

NEVES, Lucia Maria Wanderlei. Liberalismo e Educação em Debate: "Brasil Século XXI: Propostas Educacionais em Disputa. Campinas, São Paulo, Autores Associados, 2007. 
POCHMANN, Marcio. O Emprego na Globalização: a nova divisão internacional do trabalho e os caminhos que o Brasil escolheu. São Paulo: Boitempo Editorial, 2002.

SPOSITO, Marília Pontes. Juventude e políticas públicas no Brasil. In: Revista Brasileira de Educação, № 24, Set/Out/Nov/Dez 2003.

Recebido em: 30 de março de 2018. Aprovado em: 17 de maio de 2018. Publicado em: 21 de novembro de 2018. 